\title{
Listening to a Dysphonic Speaker in Noise May Impede Children's Spoken Language Processing in a Realistic Classroom Setting
}

\author{
Isabel S. Schiller ${ }^{1}$, Dominique Morsomme ${ }^{1}$, Malte $\mathrm{Kob}^{2}$, and Angélique Remacle ${ }^{1,3}$
}

${ }^{1}$ Faculty of Psychology, Speech and Language Therapy, and Educational Science, University of Liège, Belgium

${ }^{2}$ Erich Thienhaus Institute, Detmold University of Music, Germany

${ }^{3}$ Fund for Scientific Research - F.R.S. - FNRS, Brussels, Belgium

Disclosure: The authors have no conflict of interest to declare.

Funding: Published with the support of the Belgian University Foundation. Isabel S. Schiller was supported by a PhD grant from the University of Liège (no.: RD/DIR-vdu/2016.7166). Angélique Remacle was supported by the National Fund for Scientific Research - F.R.S. - FNRS, Brussels, Belgium

Corresponding Author:

Isabel S. Schiller

Rue de l'Aunaie, 30 (B38)

4000 Liège, Belgium

Phone: +3243663264

E-mail: isabel.schiller@uliege.be 
CLASSROOM LISTENING UNDER ACOUSTIC ADVERSITY

1

2 Purpose: The aim of this study was to investigate children's processing of dysphonic speech in a

3 realistic classroom setting, under the influence of added classroom noise.

4 Method: Normally developing 6-year-old primary-school children performed two listening tasks

5 in their regular classrooms: a phoneme discrimination task to assess speech perception, and a

6 sentence-picture matching task to assess listening comprehension. Speech stimuli were played

7 back in either a normal or an impaired voice quality. Children performed the tasks in the presence

8 of induced classroom noise at signal-to-noise ratios (SNR) between +2 and $+9 \mathrm{~dB}$.

9 Results: Children's performance in the phoneme discrimination task decreased significantly when

10 the speaker's voice was impaired. The effect of voice quality on sentence-picture matching

11 depended on task demands: easy sentences were processed more accurately in the impaired-voice

12 condition than in the normal-voice conditions. SNR effects are discussed in light of

13 methodological constraints.

14 Conclusions: Listening to a dysphonic teacher in a noisy classroom may impede children's

15 perception of speech, particularly when phonological discrimination is needed to disambiguate

16 the speech input. Future research regarding the interaction of voice quality and task demands is

17 necessary.

Keywords: spoken language processing, classroom noise, dysphonic voice, discrimination task, sentence comprehension task, classroom listening 
CLASSROOM LISTENING UNDER ACOUSTIC ADVERSITY

\section{Listening to a Dysphonic Speaker in Noise May Impede Children's Spoken Language Processing in a Realistic Classroom Setting}

A classroom is an environment in which children spend a considerable amount of time

22 listening to their teacher (Mealings, 2016). In doing so, they acquire knowledge and expand on that

23 knowledge as they progress through school. However, various factors may interfere with classroom

24 listening, two of them being a teacher's impaired voice quality (i.e., dysphonia) and background

25 noise. In this field study, we explored children's perception and comprehension of dysphonic

26 speech in classroom noise at classroom-typical signal-to-noise ratios (SNR).

27 Voice Impairments among Teachers

Voice impairments are a prevalent phenomenon among teachers. Every second teacher develops voice problems during their career (Roy et al., 2004). Although the etiology is not yet fully understood, underlying causes are thought to include vocal misuse or overuse in response to heavy vocal demands. Teachers with voice impairments show symptoms such as vocal fatigue,

32 throat ache, roughness, and dysphonia (Martins et al., 2014). Although their voice is their primary tool for work, only about $50 \%$ of concerned teachers seek medical treatment for voice problems

34 (Van Houtte et al., 2011). It can therefore be assumed that many children are taught by dysphonic teachers. This is problematic, because the dysphonic voice is characterized by acoustic disruptions (e.g., increased frequency perturbations [jitter], amplitude perturbations [shimmer], or a low

37 harmonics-to-noise ratio [HNR]; Teixeira \& Fernandes, 2015) which may be perceived similarly to noise. Consequently, dysphonic teachers may be less intelligible and their voices perceived as

39 unpleasant (Morsomme et al., 2011).

Classroom Noise and Room Acoustics

Background noise and poor room acoustics pose an additional challenge for classroom

42 listening. In addition to high noise levels and low SNRs, classroom acoustics are commonly 
CLASSROOM LISTENING UNDER ACOUSTIC ADVERSITY

43 evaluated based on reverberation time and Speech Transmission Index (STI). Reverberation time

44 is the time a sound takes to decay by $60 \mathrm{~dB}$ in a closed room. The STI gives an indication of the 45 quality of speech signal transmission (Steeneken \& Houtgast, 1980) and ranges between 0 and 1 -

46 the higher the value, the better the speech intelligibility.

47 The American National Standards Institute (ANSI, 2010) recommends maximum noise

48 levels of $35 \mathrm{dBA}$ and maximum reverberation times of $0.6 \mathrm{~s}$ for unoccupied classrooms. Mealings

49 (2016) suggested that, for primary-school children, who are more vulnerable to acoustic

50 interference than older peers, "good" classroom conditions apply when the following criteria are

51 met: unoccupied noise levels $<30 \mathrm{dBA}, \mathrm{SNR}>+15 \mathrm{~dB}$, reverberation time $<0.4 \mathrm{~s}$, and STI $>0.75$.

52 Unfortunately, real-world conditions often depart from these recommendations. Unoccupied noise

53 levels have been reported to vary between 41 and $51 \mathrm{dBA}$ (Crandell \& Smaldino, 2000). SNRs

54 typically range between -7 and $+11 \mathrm{~dB}$ (Bradley \& Sato, 2008; Crandell \& Smaldino, 2000).

55 Reverberation times range from 0.4 to $1.2 \mathrm{~s}$ (Crandell \& Smaldino, 2000). STI values range

56 between 0.33 and 0.88 , often below 0.75 (Mealings, 2016). A listening scenario characterized by

57 such noise interference and poor room acoustics is not ideal for classroom learning.

58 Effects of Impaired Voice and Noise on Children's Spoken Language Processing

59 The effects of a speaker's impaired voice and noise on children's spoken language

60 processing were recently investigated in a systematic review (Schiller, Remacle, et al., 2020). The

61 authors proposed a classification of impaired-voice and noise effects along three processing

62 dimensions: speech perception (referring to the initial stages of spoken language processing),

63 listening comprehension (referring to higher linguistic processing stages), and auditory working

64 memory (referring to information storage, manipulation and recall). Below, we summarize the 65 main findings.

66 Along the dimension of speech perception, impaired voice and noise may disrupt children's 
CLASSROOM LISTENING UNDER ACOUSTIC ADVERSITY

67 processing at an auditory-perceptual level and reduce intelligibility (e.g., Bradley \& Sato, 2008;

68 Howard et al., 2010; Morsomme et al., 2011; Peng \& Jiang, 2016; Peng et al., 2016). Along the

69 dimension of listening comprehension, impaired voice and noise may impede spoken language

70 processing in terms of semantic and syntactic integration (e.g., Brännström, Kastberg, et al., 2018;

71 Prodi, Visentin, Borella et al., 2019). Finally, along the dimension of auditory working memory,

72 impaired voice and noise may interfere with the storage, manipulation, and retrieval of speech-

73 encoded information (Morton \& Watson, 2001; Sullivan et al., 2015).

Regarding the dimension of listening comprehension, two laboratory studies suggested the

75 effect of impaired voice might be mediated by task demands (or cognitive demands related to

76 solving a listening task) (Lyberg-Åhlander, Haake, et al., 2015; Lyberg-Åhlander, Holm, et al.,

77 2015). Task demands depend on a combination of different factors, most of which are linguistic.

78 They include lexical and semantic aspects, word or sentence length, syntactic structure, and even

79 visual aspects related to response images. Lyberg-Åhlander, Haake, et al. (2015) found that

80 children's performance in a sentence-picture matching task decreased significantly when listening

81 to a dysphonic speaker, but only in the case of grammatically difficult sentences. In the study by

82 Lyberg-Åhlander, Holm, et al. (2015), children with strong working memory skills had less trouble

83 comprehending a dysphonic speaker than children with weaker skills, but only in the case of

84 grammatically easy sentences. The nature of the interaction between task demands and a speaker's

85 voice quality remains unclear and has never been investigated in a field experiment. Thus, this

86 study takes a closer look at the influence of task demands on children's comprehension of

87 dysphonic speech.

\section{Methodological Considerations: Laboratory versus Field Experiments}

The traditional approach to explore the effects of acoustically degraded speech on 
91 von Lochow, et al., 2018; Lyberg-Åhlander, Haake, et al., 2015; Lyberg-Åhlander, Holm, et al.,

92 2015; Sullivan et al., 2015). In these experiments, children typically perform listening tasks in quiet

93 rooms at school or in laboratories; they are tested individually or in small groups, and listen to

94 speech stimuli via earphones. Laboratory experiments offer a high degree of internal validity.

95 Controlling for confounding factors, such as reverberation time or unwanted sounds, is relatively

96 easy. A drawback is the limited generalizability of the results, due to the artificial setup.

Field experiments offer greater ecological validity because they are carried out under more authentic conditions (e.g., Bradley \& Sato, 2008; Peng \& Jiang, 2016; Peng et al., 2016; Prodi,

99 Visentin, Borella et al., 2019). By field experiments, we mean listening experiments conducted in a naturalistic setting (preferably in children's habitual classrooms), with children tested in groups (preferably together with their classmates), and speech stimuli presented in a diffuse field (via loudspeakers). The drawbacks of field experiments are that the internal validity is lower and the effects of interest may be superimposed by confounding factors. Moreover, in most cases, it may not be possible to collect response times.

To bridge the gap between internal and ecological validity, this field experiment builds on a design that we previously applied in a laboratory experiment (Schiller, Morsomme, et al., 2020), where we investigated the effects of noise and a speaker's impaired voice in a highly controlled setting. Normally developing 6-year-old children performed a phonological discrimination task (to assess speech perception), and a sentence-picture matching task (to assess listening comprehension). They were tested in quiet rooms at school. Speech stimuli were presented via 111 earphones in four conditions: normal voice in quiet, impaired voice in quiet, normal voice in noise, 112 and impaired voice in noise (speech-shaped noise at $0 \mathrm{~dB}$ SNR). The results revealed that impaired 113 voice and noise lowered performance and slowed down children's responses in the discrimination task. As for sentence-picture matching, there was an interaction between noise and voice quality: 
CLASSROOM LISTENING UNDER ACOUSTIC ADVERSITY

115 noise disrupted children's performance when the speaker's voice was impaired, but not when it

116 was normal. These findings provided a first indication that a teacher's impaired voice and noise

117 might be detrimental for classroom listening. Whether these results hold true under more realistic

118 circumstances was the starting basis of this work.

119 The aim of this study was to investigate the effects of a speaker's impaired voice and noise

120 (at classroom-typical SNRs) on children's spoken language processing in a real classroom setting.

121 A secondary aim was to document the acoustic conditions in the classrooms and take into account

122 their potential effects on children's results in listening tasks. We used the same listening tasks as

123 in Schiller, Morsomme, et al. (2020), measuring children's performance (but not response times)

124 under different listening conditions. The participants were a new set of normally developing 6-year

125 old children. Children were examined in their habitual classrooms, together with their peers, and

126 during regular school hours. Three hypotheses were tested:

127 - H1: Listening to an impaired voice will reduce children's performance in the speech $128 \quad$ perception task. particularly when listening to an impaired voice.

\section{Methods}

\section{Participants}

The participant selection procedure is depicted in Figure 1. Participants were first-graders recruited from eight primary schools in the French-speaking region of Belgium. From a total of 
CLASSROOM LISTENING UNDER ACOUSTIC ADVERSITY

138 compliance with the inclusion criteria presented below. Statistical analyses were run on a final 139 sample of 77 children ( 38 girls, 39 boys) with a mean age of $6 ; 6$ years ( $S D=3$ months).

mother tongue; (c) normal auditory development; (d) normal speech-language development; (e)

142 hearing threshold $\leq 25 \mathrm{~dB}$ HL at octave frequencies between 500 and $4000 \mathrm{kHz}$; (f) normal or

143 above-normal receptive lexical skills (i.e., score $\geq 25$ th percentile in the LexR subtest of the

144 Évaluation du Langage Oral (ELO) [Oral Language Assessment]; Khomsi, 2001); and (g) normal

145 or above-normal auditory selective attention (i.e., score $\geq 25$ th percentile in the AA subtest of the

146 Bilan NEuroPSychologique de L'Enfant 2 (NEPSY-II) [Developmental NEuroPSYchological

147 Assessment]; Korkman et al., 2007).

148 Compliance with criteria (a) to (d) was evaluated based on parental report, using a self149 administered questionnaire. Compliance with criteria (e) to (g) was based on the results of pre150 tests. In these pre-tests, children individually underwent a pure-tone audiometric screening 151 (MAICO-MA 50 audiometer with DD45 earphones) and performed the receptive lexical task 152 (Khomsi, 2001) and the auditory selective attention task (Korkman et al., 2007).

153 Oral informed consent was obtained from the participants and written informed consent 154 from their parents. This study was approved by the ethics committee of the Faculty of Psychology, 155 Speech and Language Therapy, and Education (University of Liège, Belgium; file no. 1617-54).

\section{Tasks}

Children performed two listening tasks. Speech perception was assessed with the Épreuve 158 Lilloise de Discrimination Phonologique (ELDP; Macchi et al., 2012), and listening 159 comprehension with the C2 subtest from the ELO (Khomsi, 2001). For the purpose of this study, 160 we created pen-paper versions of both tasks and used speech stimuli recorded for this research 161 project (available from the NODYS database; Schiller et al., 2019a). 
CLASSROOM LISTENING UNDER ACOUSTIC ADVERSITY

162

163

164

165

166

167

168

169

170

171

172

173

174

175

176

177

178

179

180

181

182

183

184

185

\section{Speech Perception}

The ELDP task (Macchi et al., 2012) is a phonological discrimination task. Children listen to pairs of pseudo-words (i.e., nonexistent words that comply with the phonotactic rules of French) and have to decide whether the two words sounded the same or different. We used list 1 of the ELDP task, developed for 5- to 6-year-old children. This list includes 36 speech items (pseudoword pairs). Half of them consist of two identical pseudo-words, the other half of two slightly different pseudo-words, such as /parum/ - /pamuR/ (structural opposition) or /muko/- /luko/ (phonemic opposition). In the original task, children respond by pointing to response images of either two identical-looking planets (words sounded the same) or different-looking planets (words sounded different). In our version of the task, participants circled the planet images in their answer booklets. Correct responses were coded as 1 , incorrect responses as 0 .

\section{Listening Comprehension}

The C2 subtest from the ELO (Khomsi, 2001) is a sentence-picture matching task, designed for 5- to 10-year-old children. The children's task is to listen to a sentence and match it to the corresponding picture. Each target picture is presented along with three distractors, which are morphosyntactically or semantically similar. The task contains a total of 32 sentence items of varying complexity, but can be stopped after item 21 . We chose this option, due to our participants' young age and because they had to perform the speech perception task in the same session. To account for the varying complexity, we classified the items into three levels of task demand, based on the ELO norm data. Items closest to the median performance level of $65 \%$ were classified as medium items $(\mathrm{n}=7)$. Items with higher and lower performance levels were respectively classified as easy $(n=7)$ and difficult $(n=7)$ items. In the original task, children respond by pointing. In our version of the task, they circled the corresponding pictures in their answer booklets. Correct responses were encoded as 1 , incorrect responses as 0 . 
CLASSROOM LISTENING UNDER ACOUSTIC ADVERSITY

\section{Listening Conditions}

Children performed the speech perception task and the listening comprehension task in their normal classrooms. We manipulated the speaker's voice quality and the background noise condition. As for voice quality, items were randomly presented in a normal voice or an impaired voice. Concerning noise, we played back classroom noise throughout the entire experiment. SNRs varied between +2 and $+9 \mathrm{~dB}$ (range $=8 \mathrm{~dB}$ ), as is typical for teaching situations (Bradley $\&$ Sato, 2008; Crandell \& Smaldino, 2000). This SNR range is narrow considering that the just-noticeable difference in SNR has been claimed to be around $3 \mathrm{~dB}$ (McShefferty et al., 2015). However, past studies have shown that even small differences of 3 to $4 \mathrm{~dB}$ SNR may affect children's performance in speech perception (Howard et al., 2010) and listening comprehension tasks (Valente et al., 2012). In the following sections, we provide more information on the speech and noise signals and on the experimental setup.

\section{Speech Signals}

Speech items for both listening tasks were recorded in two voice-quality conditions. The speaker was a female speech therapist, who first read out all items in her normal voice and then while mimicking dysphonia. We followed the recording guidelines outlined in Barsties and De Bodt (2015). Schiller et al. (2019b) described the characteristics of the two voice qualities. The acoustic analysis included the Acoustic Voice Quality Index (AVQI; Maryn et al., 2010), as well as jitter, shimmer, and HNR measures on sustained vowels. The perceptual analysis included a GRBAS rating (Hirano, 1981) on connected speech and sustained vowels, as well as consistency and authenticity ratings of the voice qualities. Acoustic and perceptual analyses confirmed that (a) the speaker's normal voice was free of a voice disorder $(\mathrm{AVQI}=2.53$; jitter $($ local $)=0.31 \%$; shimmer $($ local $\left.)=1.39 \% ; \mathrm{HNR}=25 \mathrm{~dB} ; \mathrm{G}_{0} \mathrm{R}_{0} \mathrm{~B}_{0} \mathrm{~A}_{0} \mathrm{~S}_{0}\right) ;($ b) the speaker's imitated impaired voice was moderately to severely dysphonic and characterized by a high degree of roughness and asthenia 
CLASSROOM LISTENING UNDER ACOUSTIC ADVERSITY

$210\left(\mathrm{AVQI}=6.89 ;\right.$ jitter $($ local $)=2.77 \% ;$ shimmer $($ local $\left.)=9.18 \% ; \mathrm{HNR}=11 \mathrm{~dB} ; \mathrm{G}_{3} \mathrm{R}_{3} \mathrm{~B}_{2} \mathrm{~A}_{3} \mathrm{~S}_{1}\right) ;$ and

211 (c) the speaker's imitated impaired voice showed a consistent quality throughout the recordings

212 and was perceived as reasonably authentic. Note that the same speech stimuli were used in our

213 laboratory experiment (Schiller, Morsomme, et al., 2020), which allows for a direct comparison.

214 Classroom Noise

215 The noise signal was classroom noise, recorded during a mathematics class in a fourth216 grade primary-school classroom. Our rationale was to use a realistic noise source that children

217 would actually encounter during regular classroom listening. Therefore, we decided not to use 218 speech-shaped noise as we did in Schiller, Morsomme, et al. (2020). For the recording, we used a 219 binaural headset (BHS II, Head acoustics). Signal processing was conducted in Praat version 6.0.29 220 (Boersma \& Weenink, 2017). We cut out all intelligible speech segments from the recording, as 221 well as the most prominent noise bursts visually detected in the spectrum. The resulting signal 222 contained typical ambient noise found in a classroom (i.e., children clearing their throat, opening 223 pencil cases, moving chairs, rustling paper, and occasionally whispering). The RMS level was 224 normalized to $50 \mathrm{~dB}$ SPL, with a dynamic range of $30 \mathrm{~dB}(32-62 \mathrm{~dB})$. Finally, we looped and time225 shifted the signal to create two 45-minute noise chains (Noise A and Noise B), identical in spectral 226 and temporal characteristics but with different starting points. In the listening experiment, we 227 simultaneously played back these noise chains from diagonally aligned loudspeakers to create a 228 realistic listening experience.

\section{Experimental Setup, Calibration, and Acoustic Measurements}

The listening experiment was conducted in eight primary school classrooms. Table 1 lists 231 information regarding the experimental context for each classroom. Figure 2 shows a typical 232 classroom setup. All classrooms were prepared in the same way. In each corner of the room, we 233 positioned one loudspeaker (Neumann KH $120 \mathrm{~A}$ ) to broadcast the classroom noise. In front of the 
CLASSROOM LISTENING UNDER ACOUSTIC ADVERSITY

234 class, where the teacher would normally stand, we positioned a fifth loudspeaker (Neumann KH

235120 A) to broadcast the speech signals. The loudspeakers were connected to and controlled from a

236 Dell laptop via an audio interface (RME Babyface Pro). Chairs were arranged in four rows of seats

237 (R1 to R4; Figure 2). Between the two middle rows (R2 and R3), we defined a central measurement

238 position (CMP). In that position, we calibrated speech and noise presentation levels. SNRs were

239 measured at the CMP and each seat row.

240 Presentation levels were calibrated in unoccupied classrooms. We leveled speech and noise

241 signals in the CMP to $\sim 70$ and $\sim 65 \mathrm{dBA}$ (fast, A-weighted sound levels), respectively, as measured

242 with a calibrated Class 2 sound level meter (NL-21, Rion), which was positioned on a microphone

243 stand. Calibration was done based on quasi-stationary speech-shaped noise (same RMS level as

244 speech and noise signals). First, we broadcast the calibration signal from the speech loudspeaker

245 and adjusted the volume until the sound level meter in the CMP steadily showed $\sim 70 \mathrm{dBA}$. The

246 same procedure was applied for the noise loudspeakers, to yield a sound level of $\sim 65 \mathrm{dBA}$. After

247 calibration, we used the sound level meter to measure SNRs per seat row by moving the

248 microphone stand to the seating positions in the center of each row. The resulting $+5 \mathrm{~dB}$ SNR in

249 the CMP, as well as the subsequently measured SNRs in each seat row (Table 1) should be regarded

250 as best-estimated fits, not exact or constant ratios. Uncertainties arise from the calibrated accuracy

251 of the sound level meter $( \pm 2 \mathrm{~dB})$, natural intensity fluctuations of speech and noise signals across

252 time, and additional noise caused by the presence of children in the room.

In each classroom, we also assessed the inherent acoustic conditions. This evaluation was

254 based on reverberation time, STI, unoccupied noise levels, and occupied noise levels.

255 Reverberation time $\left(\mathrm{T}_{30}\right)$, and STI were derived from room impulse responses in octave bands from

$25660 \mathrm{~Hz}$ to $4 \mathrm{kHz}$. For this purpose, we used WinMF Measurement Software (Four Audio, 2018).

257 The unoccupied classroom was excited with a sine sweep signal radiated from the four noise 
CLASSROOM LISTENING UNDER ACOUSTIC ADVERSITY

258 loudspeakers, which were directed towards the CMP. The receiver was an omnidirectional MM1

259 microphone (Beyeracoustics) located in the CMP. Due to time restrictions, we did not vary receiver

260 positions. Impulse responses were digitized and later used for calculating reverberation time and

261 STI. Noise levels were measured using the NL-21 sound level meter, which was located in the

262 CMP. Unoccupied noise levels ( $\mathrm{L}_{\mathrm{Aeq}}, 5 \mathrm{~min}$., in $\mathrm{dBA}$ ) were measured in empty classrooms.

263 Occupied noise levels ( $\mathrm{L}_{\mathrm{Aeq}}, 1 \mathrm{~min}$., in $\mathrm{dBA}$ ) were measured in the presence of all participants, 264 who were instructed to sit silently at their desks.

\section{Procedure}

We conducted a pilot study with a group of seven children aged 6 years old. They were 267 tested in a meeting room at University of Liège. This pilot study helped us to determine appropriate 268 presentation levels for speech and noise signals, improve the clarity of the task instructions and 269 answer booklets, and estimate how much time would be required for experimental setup, 270 calibration, and acoustic measurements (about $45 \mathrm{~min}$.), to run the experiment (about $35 \mathrm{~min}$.), and 271 to remove the material (about $15 \mathrm{~min}$. ).

The main experiment was carried out between December 2018 and March 2019 in eight

273 Belgian primary schools. During the two days that preceded the experiment in each school, children 274 were assessed for compliance with the inclusion criteria. On the day of the experiment, while the 275 school was still closed, three experimenters set up the material in the participants' habitual 276 classroom. One experimenter calibrated the speech and noise presentation levels and took the 277 acoustic measurements (except occupied noise levels). The experiment was then conducted in the 278 first hour of the morning. As children entered the room, they were assigned random seating 279 positions. Tables were equipped with screens (to prevent copying), answer booklets, and pens (see 280 Appendix). 
CLASSROOM LISTENING UNDER ACOUSTIC ADVERSITY

After ensuring that all children were quietly seated, we measured occupied noise levels.

Then the experiment was explained and the instructions for the first task (speech perception task) were read out: "You will listen to pairs of fantasy words. After each pair, your task is to decide whether the two words sounded the same or different. If they sounded the same, circle the picture of the planets that look exactly the same. If they sounded different, circle the image with the different-looking planets. Sometimes, it will be difficult to understand the speaker, because her voice sounds a bit rough. There will also be noise in the background. Just try to focus on the task and answer as best you can." The task began with four practice items, followed by the 36 test items.

Response time was restricted to 8 seconds per item, based on the maximum response times in Schiller, Morsomme, et al. (2020). Speech items were randomly presented in a normal vs. an impaired voice quality. SNRs varied depending on where participants were seated (i.e., children in the back rows performed the task under poorer SNRs than children in the front rows; see Table 1). The speech perception task was directly followed by the listening comprehension task. The experimenter explained: "In this task, you will listen to sentences. Each sentence is accompanied by four pictures that you can see in your answer booklet. Your task is to circle the picture that matches the sentence you have heard. Again, understanding the speaker might be difficult, so listen carefully, focus on your task, and answer as best you can." The task began with four practice items, followed by the 21 test items, which were played randomly in a normal or an impaired voice. SNRs remained the same as in the speech perception task. Response time was limited to 12 seconds per item, based on maximum response times in Schiller, Morsomme, et al. (2020). After the experiment, we collected the response booklets and removed the material.

\section{Statistical Analysis}

To statistically analyze the listening task data, we fitted generalized linear mixed-effects models (GLMM) using R software, version 3.6.1 (R Core Team, 2019). This was done with the 
CLASSROOM LISTENING UNDER ACOUSTIC ADVERSITY

305 glmer function of the lme4 package, version 1.1-15 (Bates et al., 2015). The assumed significance

306 level was $\alpha=.05$. We modeled our data with GLMMs, because GLMMs do not require a prior 307 transformation of binary data (Lo \& Andrews, 2015). Furthermore, our study design included 308 repeated measures, which may be accounted for in GLMMs by introducing random effects.

We built different models for the speech perception task and the listening comprehension task. GLMMs were specified with a binomial distribution and logit link function as in Schiller, 311 Morsomme, et al. (2020). A forward procedure was used for model selection (Prodi, Visentin, 312 Peretti, et al., 2019). Using R's anova function, models were compared based on the Akaike 313 Information Criterion (Akaike, 1974). Significant effects were further investigated in pairwise 314 comparisons using the lsmeans package (Lenth, 2016), with Tukey's HSD test accounting for 315 multiple comparisons.

The final speech perception model predicted children's performance as a function of the

317 fixed factors voice quality (normal vs. impaired) and $S N R$ (continuous variable ranging from +2 to $318+9 \mathrm{~dB}$ ). Our rationale for treating $S N R$ as a continuous variable was related to the narrow range of 319 SNR values (i.e., +2 to $+9 \mathrm{dBA}$ ) resulting from the presentation-level calibration that was 320 conducted within each of the eight classrooms. The GLMM included random intercepts for effects 321 of participant $(n=77)$, item $(n=36)$, discrimination target (same vs. different), trial $(n=36)$, and 322 school $(n=8)$. The final listening-comprehension model predicted performance as a function of 323 the interaction term voice quality $\mathrm{x}$ task demands (easy vs. medium vs. difficult) and SNR, 324 considering the random effects of participant and item.

\section{Results}

In the following sections, we will first report on the acoustic conditions in the eight 327 classrooms in which the experiments were conducted, and whether they affected children's 
CLASSROOM LISTENING UNDER ACOUSTIC ADVERSITY

328 listening performance. Then we present the results regarding children's performance in the speech

329 perception task and the listening comprehension task.

330 Classroom Acoustics

331 To reduce the impact of varying classroom acoustics on the results, we normalized speech

332 and noise presentation levels in each classroom by means of calibration. As this does not cancel

333 out all room-related differences, we further considered the following acoustic parameters in our

334 statistical analyses: reverberation time, STI, unoccupied noise levels, and occupied noise levels.

335 Table 2 shows the respective measurement results. Unoccupied noise levels varied between 37 and

$33645 \mathrm{dBA}$. Occupied noise levels varied between 43 and $50 \mathrm{dBA}$. Note that the highest occupied

337 noise levels were measured in classroom 8, although this classroom exhibited the lowest

338 unoccupied noise levels. Reverberation times varied between 0.4 and 0.8 s. Finally, STI values

339 ranged from 0.69 and 0.89.

340 The potential influence of these acoustic parameters on children's performance was 341 assessed by treating them as random effects in the GLMMs of both tasks. Other random effects 342 assessed in the GLMMs were children's age and gender. None of these random effects resulted in 343 a statistically significant improvement of the model fits, so they were dropped from the final 344 GLMMs. Reasons for a factor's incapacity to improve the model fits could be a poor predictive 345 value with regard to the dependent variable or the fact that including this factor would have resulted 346 in overfitting.

\section{The Effect of Voice Quality}

Figure 3 illustrates children's performance in the two listening tasks as a function of voice 349 quality. Results from the GLMMs revealed that, in the speech perception task, children's 350 performance was statistically significantly impeded by a speaker's impaired voice $\left(\chi^{2}(1)=10.3, p\right.$ $351=.001)$. Figure 3 shows the performance drop from a proportion-correct level of $0.79(S E=0.13$, 
CLASSROOM LISTENING UNDER ACOUSTIC ADVERSITY

$352 \mathrm{CI}[0.45,0.94])$ in the normal-voice condition to 0.73 (SE $=0.15$, CI $[0.37,0.92])$ in the impaired-

353 voice condition, indicating that children discriminated phonemes in pseudo-words with about $8 \%$

354 lower accuracy. There was no main effect of voice quality on children's performance in the

355 listening comprehension task $\left(\chi^{2}(1)=0.2, p=.62\right)$.

356 Interaction between Voice Quality and Task Demands

While voice quality alone had no statistically significant effect on children's listening comprehension, GLMM results revealed a statistically significant interaction between voice quality and task demands $\left(\chi^{2}(2)=11.07, p=0.004\right)$. This interaction is depicted in Figure 4. Contrary to our expectations, pairwise comparisons by means of Tukey's HSD test showed a statistically significantly weaker performance for the normal voice than the impaired voice, when children listened to easy sentences $(z=3.0, p=0.03)$. Under this condition, the GLMM estimated proportion-correct levels of $0.78(S E=0.06, \mathrm{CI}[0.63,0.88])$ for the normal voice and $0.88(S E=$ 0.04, CI [0.78, 0.94]) for the impaired voice. When sentences were of medium difficulty, performance was slightly but not statistically significantly better in the normal-voice condition $(z$ $=-1.54, p=0.64)$. In the case of difficult sentences, performance in the normal- and impairedvoice condition did not differ $(z=-0.18, p=1.0)$.

\section{The Effect of Classroom Noise}

The effect of classroom noise was assessed in terms of the numeric variable SNR. GLMM results revealed a statistically significant effect of SNR on children's performance in the speech perception task $(\beta=0.07, z=2.1, p=0.03)$, suggesting that, with a decreasing $\mathrm{SNR}$, children discriminated phonemes less accurately. However, when plotting the proportion of correct responses for each estimated SNR unit (ranging from $+2 \mathrm{~dB}$ to $+9 \mathrm{~dB}$ ), this effect appears negligible (see the left-hand graph in Figure 5). Visual inspection of the data shows considerable variance, as indicated by the large standard errors. Finally, no statistically significant interaction 
CLASSROOM LISTENING UNDER ACOUSTIC ADVERSITY

376 between SNR and voice quality $\left(\chi^{2}(1)=0.14, p=0.71\right)$ was found. Regarding listening 377 comprehension, GLMM results revealed neither a statistically significant effect of SNR $(\beta=0.02$, $378 z=0.55, p=.58$ ) nor a statistically significant interaction between SNR and voice quality $\chi^{2}(1)=$ $3790.32, p=0.57)$. The right-hand graph in Figure 5 shows the proportion of correct responses in the 380 listening task for each of the estimated SNR units (ranging from $+9 \mathrm{~dB}$ to $+2 \mathrm{~dB}$ ).

\section{Discussion}

In classrooms, pupils may frequently be required to listen to dysphonic teachers and deal with high noise levels (Crandell \& Smaldino, 2000; Martins et al., 2014; Mealings, 2016; Roy et

al., 2004; Van Houtte et al., 2011). This prompted us to carry out in-depth investigations into the 385 effects of impaired voice and noise on spoken language processing in normally developing children. In our previous works, we reviewed the literature regarding these effects and provided a classification along different processing dimensions (Schiller, Remacle, et al., 2020). In a laboratory experiment, we showed that speech-shaped noise and a speaker's impaired voice disrupt spoken language processing in 6-year-olds (Schiller, Morsomme, et al., 2020). The results from the present field experiment confirmed that these findings largely hold true under more realistic

circumstances. Beyond that, they suggested that children's processing of dysphonic speech may vary with respect to task demands. These findings will be discussed in light of the previous

393 literature.

\section{The Effect of Voice Quality}

We hypothesized that listening to a dysphonic voice would significantly impair children's 396 performance in a speech perception task (H1). Our results confirmed this hypothesis and aligned with findings from our systematic review (Schiller, Remacle, et al., 2020), our laboratory experiment (Schiller, Morsomme, et al., 2020) and another field experiment (Morsomme et al., 
CLASSROOM LISTENING UNDER ACOUSTIC ADVERSITY

400 that dysphonic speech was less intelligible. This is probably related to the increased proportion of 401 noise components in the spectrum, as indicated by the low HNR of $11 \mathrm{~dB}$ compared to a $25 \mathrm{~dB}$ 402 HNR in the normal voice. Discriminating phonemes in a dysphonic speech stream may be 403 significantly more difficult for children when they cannot deduce a word meaning from the context. 404 Interestingly, the performance drop from the normal-voice condition to the impaired-voice 405 condition was about $9 \%$ weaker than in the speech-in-noise conditions of our laboratory experiment 406 (Schiller, Morsomme, et al., 2020). We speculate that the speech-shaped noise used in Schiller, 407 Morsomme, et al. (2020) induced greater energetic masking effects (i.e., greater physical 408 overlapping of physical characteristics with the speech signal; Mattys et al., 2009) on the impaired 409 voice than the real classroom noise. The collection of response times in this study would have 410 allowed a more fine-grained comparison, especially because we previously showed that children's 411 speech-in-noise perception was not only less accurate but also slower when the speaker's voice 412 was impaired (Schiller, Morsomme, et al., 2020). Future studies are needed for an in-depth 413 investigation of the interaction between a speaker's voice quality and noise source on speech 414 perception.

415 Our second hypothesis $(\mathrm{H} 2)$ stated that listening to an impaired voice would reduce 416 children's performance in the listening comprehension task and that this effect might interact with 417 task demands (easy, medium, difficult). Taken together, our results showed no negative effect of 418 impaired voice on children's listening comprehension. This is in line with earlier findings by 419 Morton and Watson (2001) and Schiller, Morsomme, et al. (2020). However, it diverges from the 420 prevailing assumption that listening to an impaired voice (in noise) increases children's processing 421 load, thereby leaving less resources available for comprehending the spoken message (Brännström, 422 Kastberg, et al., 2018; Lyberg-Åhlander, Haake, et al., 2015; Lyberg-Åhlander, Holm, et al., 2015). 
CLASSROOM LISTENING UNDER ACOUSTIC ADVERSITY

423 We assume that increased processing load might instead manifest in prolonged response times

424 rather than in reduced task performance.

\section{Interaction between Voice Quality and Task Demands}

426 We observed an interesting interaction between voice quality and task demands. Recall that

427 task demands refer to the degree of difficulty of the 21 sentence items as derived from the ELO

428 norm data (Khomsi, 2001). These demands are thought to result predominantly from sentence

429 length, word familiarity, syntactic complexity, and semantic distance between target and distractor

430 pictures. When task demands were low (i.e., when an item results in high performance levels,

431 according to the ELO norm data) children performed statistically significantly better in the

432 impaired-voice condition than in the normal-voice condition. No such difference was found

433 regarding medium or high task demands. We suspect that two opposing effects may explain the

434 observed interaction, as explained below.

435 On the one hand, listening to an abnormal voice might have attracted children's attention

436 back to the task in a situation when their overall concentration was fading (recall that the listening

437 comprehension task was presented after the speech perception task). In other words, the impaired

438 voice might have had a standout effect, as it sounded quite different to the speech children would

439 normally encounter. In the case of easy sentences, this standout effect might have generated a

440 performance advantage by increasing children's alertness. On the other hand, in the case of more

441 difficult sentences, the increased processing demands might have outweighed the standout effect.

442 This might explain why no effect of impaired voice quality was seen for moderately and very

443 difficult sentences.

444 Our theory of the counteracting effects would also explain why Lyberg-Åhlander, Haake, 445 et al. (2015) found disruptive effects of impaired voice on children's processing of difficult 446 sentences but not of easier sentences. Note that the present study included only children with 
CLASSROOM LISTENING UNDER ACOUSTIC ADVERSITY

447 normal- and above normal auditory selective attention skills. These children might have had better

448 abilities to process dysphonic speech, which might explain why their processing of difficult

449 sentences was not impeded by the impaired voice. Lyberg-Åhlander, Holm, et al. (2015) had

450 previously provided indications that children with strong cognitive skills may be less affected by a

451 speaker's impaired voice than their peers. Future research is needed to validate statements

452 regarding the interaction between a speaker's voice quality and task demands, as well as children's

453 ability to respond to these demands.

\section{The Effect of Classroom Noise}

455 Our third hypothesis (H3) stated that children's task performance in classroom noise would 456 decline with decreasing SNR, particularly when the speaker's voice was impaired. This was not 457 confirmed by our results. Regarding the speech perception task, the effect of SNR was statistically 458 significant, concurrent with previous results from laboratory experiments (Howard et al., 2010; 459 Schiller, Morsomme, et al. 2020; Sullivan et al., 2015) and field experiments (Bradley \& Sato, 460 2008; Peng \& Jiang, 2016). However, a visual inspection of the performance data per SNR failed 461 to show a clear downward trend in performance with decreasing SNR (Figure 5). This likely relates 462 to the small SNR range combined with potential confounding factors, as is further discussed below. 463 Regarding the listening comprehension task, our statistical analysis showed no significant effect of 464 SNR. This result was similar to our previous findings (Schiller, Morsomme, et al., 2020) but 465 diverged from Valente et al.'s (2012) finding that children's performance in a listening466 comprehension task significantly decreased as the SNR dropped from +10 to +7 dBA (SNR is 467 treated as a categorical variable). Finally, no statistically significant interaction between SNR and 468 the speaker's voice quality on children's performance in either task was found.

469 For several reasons, these results should be interpreted cautiously: (1) the SNR range was 470 narrow (i.e., $8 \mathrm{dBA}$ ). Although even small SNR decreases may disrupt children's spoken language 
471 processing (Howard et al., 2010; Valente et al., 2012), a broader SNR range would have certainly

472 made detection of noise-induced performance changes more likely. (2) SNR values were positive

473 (i.e., varying between +2 and $+8 \mathrm{dBA}$ ). Particularly in the case of the listening comprehension task,

474 in which children could rely on context cues for sentence interpretation, the level of classroom

475 noise might have been too low to impede performance. Response time measures might have

476 revealed more subtle effects with regard to listening effort. (3) SNR values provide only an average

477 estimate, because speech and noise signals fluctuated and SNRs were measured before children

478 entered the classroom. Finally, (4) further uncertainties may result from the study design (e.g.,

479 varying group dynamics, individual differences) and the measurement material (e.g., $\pm 2 \mathrm{~dB}$ 480 accuracy of the sound-level meter).

481 In the context of listening comprehension, the lack of a main effect of SNR or of a 482 significant SNR x voice quality interaction on performance could also relate to practice and/or 483 habituation effects. Because the children performed the listening tasks in classroom-typical SNRs, 484 it possible that they were adept at processing speech under such conditions due to daily exposure. 485 The fact that speech-in-noise training can generally improve children's processing of speech in 486 noise was confirmed by Millward et al. (2011). The extent to which daily-life situations, such as 487 listening in a noisy classroom or living in a noisy household, may result in similar training effects 488 remains to be discovered (e.g., by increasingly integrating questionnaire data in experimental 489 studies). Given that noise was present during the entire experiment, which lasted about 35 minutes, 490 it is also possible that children became less disturbed by it over time. To date, little is known about 491 children's habituation to noise in listening tasks. However, a study in which adults had to perform 492 a working memory task in noise showed that noise habituation may be possible (Röer et al., 2014). 493 More research on this interesting topic is needed. 
CLASSROOM LISTENING UNDER ACOUSTIC ADVERSITY

\section{Considerations on the Acoustic Conditions within Classrooms}

A subordinate aim of this paper was to evaluate the acoustic conditions of the classrooms

in which the listening experiments were performed. Classroom acoustics may influence children's listening conditions and therefore need to be considered in field studies. In this study, reverberation time, STI, unoccupied noise levels, and occupied noise levels did not significantly affect children's listening-task performance. Importantly, however, the unoccupied noise levels we measured (i.e., 37-45 dBA) consistently surpassed the recommended maximum thresholds of between $30 \mathrm{dBA}$ (Mealings, 2016) and 35 dBA (ANSI, 2010). Occupied noise levels varied between $41 \mathrm{dBA}$ and $50 \mathrm{dBA}$, with the highest measure (i.e., $50 \mathrm{dBA}$ ) obtained in classroom 8 - a peculiar finding, because classroom 8 also showed the lowest unoccupied noise level (i.e., $37 \mathrm{dBA}$ ). This variation might be due to different agitation levels of the children in relation to the short measurement time of one minute. Reverberation times varied between 0.4 and $0.8 \mathrm{~s}$, with the mean of $0.59 \mathrm{~s}$ falling barely below the recommended maximum of 0.6 s (ANSI, 2010), but still surpassing Mealing's (2016) proposed threshold of 0.4 s. STI values varied between 0.69 and 0.89 , with the mean of 0.75 suggesting appropriate conditions for speech transmission (Steeneken \& Houtgast, 1980). Given the alarming classroom acoustic measures reported in the literature (Crandell \& Smaldino, 2000; Mealings, 2016), the conditions we measured across the eight classrooms can be regarded as fair but they could definitely be improved.

\section{Limitations and Future Directions}

We presented and discussed the results of a field experiment that arose from a previous laboratory experiment (Schiller, Morsomme, et al., 2020). Our adaptation of the study design allowed us to test the ecological validity of our previous findings in a more naturalistic setting. Nevertheless, there are some limitations that should be acknowledged and future directions that must be discussed. 
CLASSROOM LISTENING UNDER ACOUSTIC ADVERSITY

One limitation was the difficulty of ruling out the effects of varying classroom

519 characteristics on the results. Because we sought to test children under the most realistic

520 circumstances possible, the experiment was performed in various classrooms with different shapes

521 and acoustic conditions. To address this problem, we calibrated the sound-presentation levels in

522 order to equalize listening conditions and we included various acoustic variables in our statistical

523 models. Nevertheless, there might be other confounding factors we did not control for (e.g.,

524 different group dynamics or the duration of each individual experiment). Moreover, our procedure

525 resulted in a narrow SNR range, which might have made it difficult to detect noise effects.

526 Another limitation is that the tasks presented to the children were different from tasks they

527 would encounter during normal lessons. During lessons, children might be required to listen for a

528 sustained period of time. Tasks might require them to switch back and forth between speech

529 perception and production. We did not use such tasks, as they have their own drawbacks. Prolonged

530 speech-in-noise listening tasks preclude the assessment of low-level speech perception. Moreover,

531 standardized test material is rarely available. It would be interesting to build on the concept of

532 passage comprehension tasks, by creating a task in which children listen to and answer questions

533 about even longer texts.

534 The effects of impaired voice and noise should increasingly be investigated in relation to 535 fatigue resulting from sustained listening effort. Children might tire sooner when listening to a 536 dysphonic teacher in noise. However, the opposite effect - an adaptation to impaired voice or 537 noise - is also possible. More research is needed to understand the effect of prolonged exposure to 538 impaired voice. Whenever possible, the collection of response times is recommended and may 539 allow deeper insight into children's listening effort.

540 Conclusion 
CLASSROOM LISTENING UNDER ACOUSTIC ADVERSITY

This study was the first to assess the combined effect of a speaker's voice quality and noise

542 on school-aged children's spoken language processing in a realistic classroom setting. When the

543 speaker's voice was impaired, children had more problems processing speech in noise, as indicated

544 by the results of a phoneme discrimination task. On the level of complex listening comprehension,

545 however, no main effect of impaired voice was detected. Response time measurements might have

546 provided more subtle information regarding this question. An interesting finding was that, when

547 sentences induced few processing demands, exposure to an impaired voice appeared to improve

548 performance, possibly because it increased children's arousal. Regarding the effect of classroom

549 noise, the results precluded firm conclusions, mainly as a consequence of a narrow SNR range.

550 Our findings indicated that, even at the very beginning of primary school, children possess

551 a certain competency to restore acoustically degraded speech based on linguistic context. This

552 should not, however, tempt us to assume they are unaffected by classroom noise or by a teacher's

553 dysphonic voice. Disruptions during low-level speech perception might carry over to high-level

554 listening comprehension and make listening more effortful.

555 Finally, in terms of classroom acoustics, we showed that none of the eight primary-school

556 classrooms in which the listening tasks were carried out provided optimal listening and learning

557 conditions. Concurrently with what has been observed in international noise surveys, noise levels,

558 reverberation times, and STI values mostly deviated from the recommended standards. It is still

559 important to tackle this problem to support children's academic performance and make both 560 teaching and learning pleasant experiences.

\section{Acknowledgments}

562 The authors would like to thank the participating schools for their assistance during the

563 experiment. We also acknowledge the help of Justine Jonlet, Cloé Deflandre, Sacha Pszenica, and 564 Elsa Poncet in collecting the data. Thank you to Sysmex Belgium N.V. for providing the NL-21 
CLASSROOM LISTENING UNDER ACOUSTIC ADVERSITY

565 sound level meter used in the present study. Finally, we particularly thank the University of

566 Music in Detmold for providing the loudspeakers, measurement equipment, and audio interface. 
CLASSROOM LISTENING UNDER ACOUSTIC ADVERSITY

\section{References}

569

570

571

572

573

574

575

576

577

578

579

580

581

582

583

584

585

586

587

588

589

590

591

Akaike, H. (1974). A new look at the statistical model identification. IEEE Transactions on Automatic Control, 19(6), 716-723. https://doi.org/10.1109/TAC.1974.1100705

American National Standards Institute (ANSI). (2010). ANSI/ASA S12.60-2010/Part 1 American national standard acoustical performance criteria, design requirements, and guidelines for schools, part 1: Permanent schools. American National Standards Institute.

Barsties, B., \& De Bodt, M. (2015). Assessment of voice quality: Current state-of-the-art. Auris Nasus Larynx, 42(3), 183-188. https://doi.org/10.1016/j.anl.2014.11.001

Bates, D., Maechler, M., Bolker, B., \& Walker, S. (2015). Fitting linear mixed effects models using lme4. Journal of Statistical Software, 67(1), 1-48. https://doi.org/10.18637/jss.v067.i01

Boersma, P., \& Weenink, D. (2017). Praat (version 6.0.29) [Computer software]. http://www.fon.hum.uva.nl/praat/

Bradley, J. S., \& Sato, H. (2008). The intelligibility of speech in elementary school classrooms. The Journal of the Acoustical Society of America, 123(4), 2078-2086. https://doi.org/10.1121/1.2839285

Brännström, K. J., Kastberg, T., von Lochow, H., Haake, M., Sahlén, B., \& Lyberg-Åhlander, V. (2018). The influence of voice quality on sentence processing and recall performance in school-age children with normal hearing. Speech, Language and Hearing, 21(1), 1-9. https://doi.org/10.1080/2050571X.2017.1309787

Brännström, K. J., von Lochow, H., Lyberg-Åhlander, V., \& Sahlén, B. (2018). Immediate passage comprehension and encoding of information into long-term memory in children with normal hearing: The effect of voice quality and multitalker babble noise. American Journal of Audiology, 27, 231-237. https://doi.org/10.1044/2018_AJA-17-0061 
CLASSROOM LISTENING UNDER ACOUSTIC ADVERSITY

592 Crandell, C. C., \& Smaldino, J. J. (2000). Classroom acoustics for children with normal hearing

593 and with hearing impairment. Language, Speech, and Hearing Services in Schools, 31(4), 362-370. https://doi.org/10.1044/0161-1461.3104.362

Four Audio. (2018). WinMF Measurement Software [Computer software]. Four Audio GmbH \& Co. $\mathrm{KG}$

Hirano, M. (1981). Psycho-acoustic evaluation of voice. In G. Arnold, F. Winckel, \& B. Wyke (Eds.), Disorders of human communication (pp. 81-84). Springer.

Howard, C. S., Munro, K. J., \& Plack, C. J. (2010). Listening effort at signal-to-noise ratios that are typical of the school classroom. International Journal of Audiology, 49(12), 928-932. https://doi.org/10.3109/14992027.2010.520036

Khomsi, A. (2001). ELO: Évaluation du Langage Oral (Oral language evaluation) [Measurement instrument]. ECPA Pearson.

Korkman, M., Kirk, U., \& Kemp, S. L. (2007). NEPSY-II, 2nd ed. [Measurement instrument]. Harcourt Assessment.

Lenth, R. V. (2016). Least-squares means: The R package lsmeans. Journal of Statistical Software, 69(1), 1-33. https://doi.org/10.18637/jss.v069.i01

Lo, S., \& Andrews, S. (2015). To transform or not to transform: Using generalized linear mixed

611 Lyberg-Åhlander, V., Haake, M., Brännström, J., Schötz, S., \& Sahlén, B. (2015). Does the 612 speaker's voice quality influence children's performance on a language comprehension test? International Journal of Speech-Language Pathology, 17(1), 63-73. models to analyse reaction time data. Frontiers in Psychology, 6, 1171. https://doi.org/10.3389/fpsyg.2015.01171

615 Lyberg-Åhlander, V., Holm, L., Kastberg, T., Haake, M., Brännström, K. J., \& Sahlén, B. (2015). 
CLASSROOM LISTENING UNDER ACOUSTIC ADVERSITY

Are children with stronger cognitive capacity more or less disturbed by classroom noise and dysphonic teachers? International Journal of Speech-Language Pathology, 17(6), 577-588. https://doi.org/10.3109/17549507.2015.1024172

Macchi, L., Descours, C., Girard, É., Guitton, É., Morel, C., Timmermans, N., \& Boidein, F. (2012). ELDP: Épreuve Lilloise de Discrimination Phonologique (The Lille Test of Phonological Discrimination) [Measurement instrument]. http://orthophonie.univlille2.fr/stocks/stock-contents/epreuve-lilloise-de-discrimination-phonologique.html Martins, R. H. G., Pereira, E. R. B. N., Hidalgo, C. B., \& Tavares, E. L. M. (2014). Voice disorders in teachers. A review. Journal of Voice, 28(6), 716-724. https://doi.org/10.1016/j.jvoice.2014.02.008

Maryn, Y., Corthals, P., Van Cauwenberge, P., Roy, N., \& De Bodt, M. (2010). Toward improved ecological validity in the acoustic measurement of overall voice quality: Combining continuous speech and sustained vowels. Journal of Voice, 24(5), 540-555. https://doi.org/10.1016/j.jvoice.2008.12.014

Mattys, S. L., Brooks, J., \& Cooke, M. (2009). Recognizing speech under a processing load: Dissociating energetic from informational factors. Cognitive Psychology, 59(3), 203-243. https://doi.org/10.1016/j.cogpsych.2009.04.001

McShefferty, D., Whitmer, W. M., \& Akeroyd, M. A. (2015). The just-noticeable difference in speech-to-noise ratio. Trends in Hearing, 19, 1-9. https://doi.org/10.1177/2331216515572316

Mealings, K. (2016). Classroom acoustic conditions: Understanding what is suitable through a review of national and international standards, recommendations, and live classroom measurements. In I. D. M. Hillock \& D. J. Mee (Eds.), Proceedings of Acoustics 2016: The Second Australasian Acoustical Societies Conference (pp. 1047-1056). The Australian 
CLASSROOM LISTENING UNDER ACOUSTIC ADVERSITY

640

641

642

643

644

645

646

647

648

649

650

651

652

653

654

655

656

657

658

659

660

661

662

663

Acoustical Society

Millward, K. E., Hall, R. L., Ferguson, M. A., \& Moore, D. R. (2011). Training speech-in-noise perception in mainstream school children. International Journal of Pediatric

Otorhinolaryngology, 75(11), 1408-1417. https://doi.org/10.1016/j.ijporl.2011.08.003

Morsomme, D., Minell, L., \& Verduyckt, I. (2011). Impact of teachers' voice quality on children's language processing skills. VOCOLOGIE: Stem en Stemstoornissen, 9-15.

Morton, V., \& Watson, D. R. (2001). The impact of impaired vocal quality on children's ability to process spoken language. Logopedics Phoniatrics Vocology, 26(1), 17-25. https://doi.org/10.1080/14015430118232

Peng, J., \& Jiang, P. (2016). Chinese word identification and sentence intelligibility in primary school classrooms. Archives of Acoustics, 41(2), 213-219. https://doi.org/10.1515/aoa-20160021

Peng, J., Zhang, H., \& Yan, N. (2016). Effect of different types of noises on Chinese speech intelligibility of children in elementary school classrooms. Acta Acustica United with Acustica, 102(5), 938-944. https://doi.org/10.3813/AAA.919008

Prodi, N., Visentin, C., Borella, E., Mammarella, I. C., \& Di Domenico, A. (2019). Noise, age, and gender effects on speech intelligibility and sentence comprehension for 11- to 13-yearold children in real classrooms. Frontiers in Psychology, 10, 2166. https://doi.org/10.3389/fpsyg.2019.02166

Prodi, N., Visentin, C., Peretti, A., Griguolo, J., \& Bartolucci, G. B. (2019). Investigating listening effort in classrooms for 5- to 7-year-old children. Language, Speech, and Hearing Services in Schools, 50(2), 196-210. https://doi.org/10.1044/2018_LSHSS-18-0039

R Core Team. (2019). R: A language and environment for statistical computing [Computer software]. https://www.R-project.org/ 
CLASSROOM LISTENING UNDER ACOUSTIC ADVERSITY

664 Röer, J. P., Bell, R., \& Buchner, A. (2014). Evidence for habituation of the irrelevant-sound

665 effect on serial recall. Memory and Cognition, 42(4), 609-621.

666 https://doi.org/10.3758/s13421-013-0381-y

667 668

Roy, N., Merrill, R. M., Thibeault, S., Parsa, R. A., Gray, S. D., \& Smith, E. M. (2004). Prevalence of voice disorders in teachers and the general population. Journal of Speech, Language, and Hearing Research, 47, 281-293. https://doi.org/10.1044/1092$4388(2004 / 023)$

Schiller, I. S., Morsomme, D., Kob, M., \& Remacle, A. (2020). Noise and a speaker's impaired voice quality disrupt spoken language processing in school-aged children: Evidence from performance and response time measures. Journal of Speech, Language, and Hearing Research, 63(7), 2115-2131.

Schiller, I. S., Remacle, A., Durieux, N., \& Morsomme, D. (2020, January 9-10). The effects of noise and impaired voice quality on spoken language processing in school-aged children: Preliminary results of a systematic review [poster presentation]. The $12^{\text {th }}$ Speech in Noise (SPIN) Workshop, Toulouse, France.

Schiller, I. S., Remacle, A., \& Morsomme, D. (2019a). NODYS: NOrmophonic and DYsphonic Speech samples, Mendeley Data, v1 [Database]. Mendeley. https://doi.org/10.17632/g2fmkw8t85.1

Schiller, I. S., Remacle, A., \& Morsomme, D. (2019b). Imitating dysphonic voice: A suitable technique to create speech stimuli for spoken language processing tasks? Logopedics Phoniatrics Vocology, 1-8. https://doi.org/10.1080/14015439.2019.1659410

Steeneken, H. J. M., \& Houtgast, T. (1980). A physical method for measuring speechtransmission quality. The Journal of the Acoustical Society of America, 67(1), 318-326. https://doi.org/10.1121/1.384464 
CLASSROOM LISTENING UNDER ACOUSTIC ADVERSITY

688 Sullivan, J. R., Osman, H., \& Schafer, E. C. (2015). The effect of noise on the relationship

689 between auditory working memory and comprehension in school-age children. Journal of

690 Speech, Language, and Hearing Research, 58(3), 1043-1051.

691 https://doi.org/10.1044/2015_JSLHR-H-14-0204

692 Teixeira, J. P., \& Fernandes, P. O. (2015). Acoustic analysis of vocal dysphonia. Procedia

693 Computer Science, 64, 466-473. https://doi.org/10.1016/j.procs.2015.08.544

694 Valente, D. L., Plevinsky, H. M., Franco, J. M., Heinrichs-Graham, E. C., \& Lewis, D. E. (2012).

695 Experimental investigation of the effects of the acoustical conditions in a simulated

696 classroom on speech recognition and learning in children. The Journal of the Acoustical

697 Society of America, 131(1), 232-246. https://doi.org/10.1121/1.3662059

698 Van Houtte, E., Claeys, S., Wuyts, F., \& Van Lierde, K. (2011). The impact of voice disorders

699 among teachers: Vocal complaints, treatment-seeking behavior, knowledge of vocal care,

700 and voice-related absenteeism. Journal of Voice, 25(5), 570-575.

$701 \quad$ https://doi.org/10.1016/j.jvoice.2010.04.008 


\section{Table 1}

703

Information regarding the experimental setting and the artificially induced SNRs in the eight classrooms.

\begin{tabular}{|c|c|c|c|c|c|c|c|c|c|c|}
\hline \multirow{4}{*}{$\begin{array}{c}\text { Classroom } \\
\text { ID }\end{array}$} & \multirow{4}{*}{$\begin{array}{l}\text { Room } \\
\text { volume } \\
\left(\text { in } \mathrm{m}^{3} \text { ) }\right.\end{array}$} & \multirow{4}{*}{$\begin{array}{l}\text { Children present } \\
\text { during experiment } \\
(N)\end{array}$} & \multicolumn{4}{|c|}{ Distance between speech source } & \multicolumn{4}{|c|}{ SNR per seat row ${ }^{a}(\mathrm{R} 1-\mathrm{R} 4)$} \\
\hline & & & \multicolumn{8}{|c|}{ and seat rows (R1-R4) } \\
\hline & & & \multicolumn{4}{|c|}{ (in m) } & \multicolumn{4}{|c|}{ (in $\mathrm{dB}$ ) } \\
\hline & & & $\mathrm{R} 1$ & $\mathrm{R} 2$ & $\mathrm{R} 3$ & $\mathrm{R} 4$ & R1 & $\mathrm{R} 2$ & $\mathrm{R} 3$ & $\mathrm{R} 4$ \\
\hline 1 & 214 & 16 & 1.2 & 2.3 & 3.0 & 4.2 & 9 & 8 & 5 & 3 \\
\hline 2 & 129 & 20 & 1.2 & 2.3 & 3.2 & 4.3 & 8 & 7 & 5 & 4 \\
\hline 3 & 213 & 15 & 1.1 & 2.3 & 3.6 & 4.9 & 9 & 6 & 4 & 3 \\
\hline 4 & 124 & 20 & 0.7 & 1.7 & 2.9 & 4.2 & 7 & 6 & 2 & 0 \\
\hline 5 & 121 & 19 & 2.1 & 3.3 & 4.5 & 5.7 & 6 & 5 & 4 & 3 \\
\hline 6 & 168 & 19 & 1.3 & 2.4 & 3.9 & 4.9 & 7 & 6 & 5 & 4 \\
\hline 7 & 59 & 14 & 0.9 & 1.9 & 2.5 & - & 6 & 5 & 4 & - \\
\hline 8 & 118 & 18 & 1.2 & 2.2 & 3.4 & 4.6 & 9 & 5 & 3 & 2 \\
\hline Mean & 143 & 18 & 1.2 & 2.3 & 3.4 & 4.7 & 8 & 6 & 4 & 3 \\
\hline
\end{tabular}

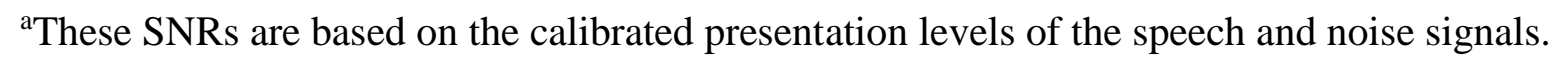




\section{Table 2}

706 Descriptive results from the acoustic measurements taken in the eight classrooms

Class- Unoccupied Occupied RT $^{\mathrm{a}} \quad$ STI $^{\mathrm{b}}$

room noise level noise level

ID $\quad\left(L_{a e q}\right.$ in $\left.d B\right) \quad\left(L_{a e q}\right.$ in $\left.d B\right) \quad\left(T_{30}\right.$ in

$s)$

\begin{tabular}{lllll}
\hline 1 & 45 & 49 & 0.52 & 0.76 \\
2 & 38 & 42 & 0.79 & 0.67 \\
3 & 38 & 49 & 0.45 & 0.78 \\
4 & 40 & 41 & 0.36 & 0.89 \\
5 & 39 & 47 & 0.73 & 0.69 \\
6 & 43 & 49 & 0.72 & 0.70 \\
7 & 37 & 43 & 0.60 & 0.73 \\
8 & 37 & 50 & 0.52 & 0.76 \\
\hline Mean & 40 & 46 & 0.59 & 0.75
\end{tabular}

$707 \quad{ }^{\mathrm{a}} \mathrm{RT}=$ Reverberation time

$708 \quad{ }^{\mathrm{b}} \mathrm{STI}=$ Speech Transmission Index 


\section{$709 \quad$ Figure 1}

158 questionnaires and consent forms distributed

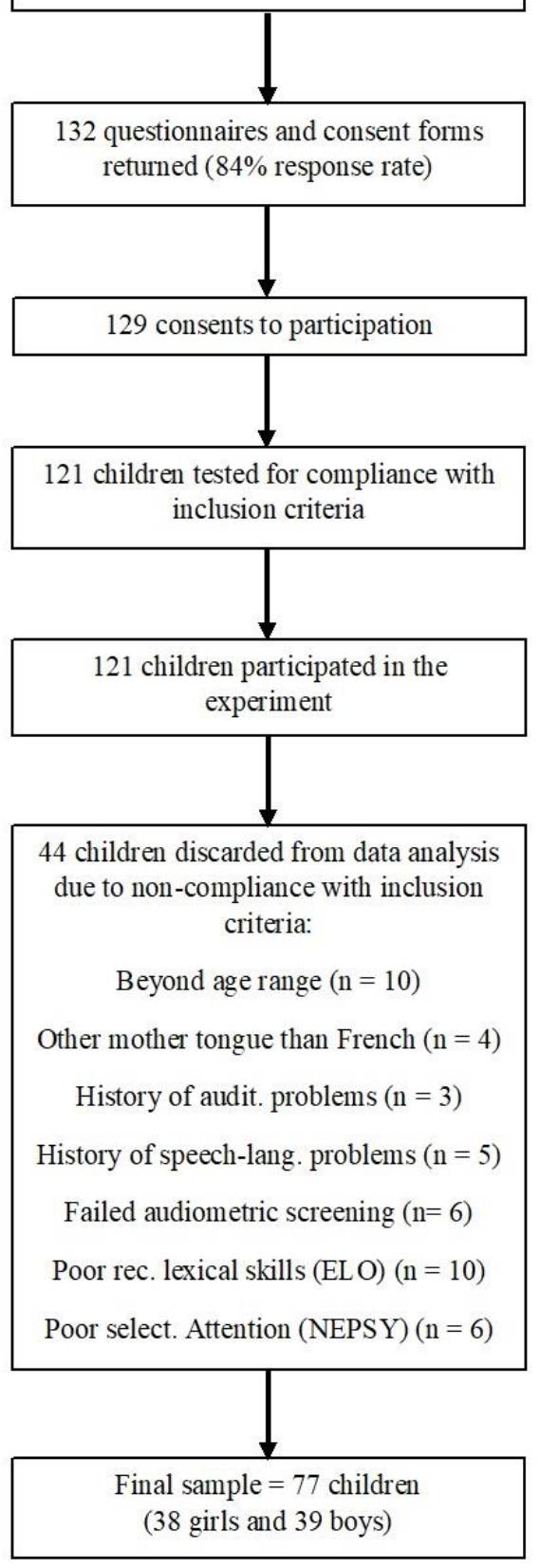

712 Note. Eight children who consented to participate were absent on the days when we assessed

713 children's compliance with the inclusion criteria. 
$714 \quad$ Figure 2

715 Diagram of the typical experimental setup in each classroom

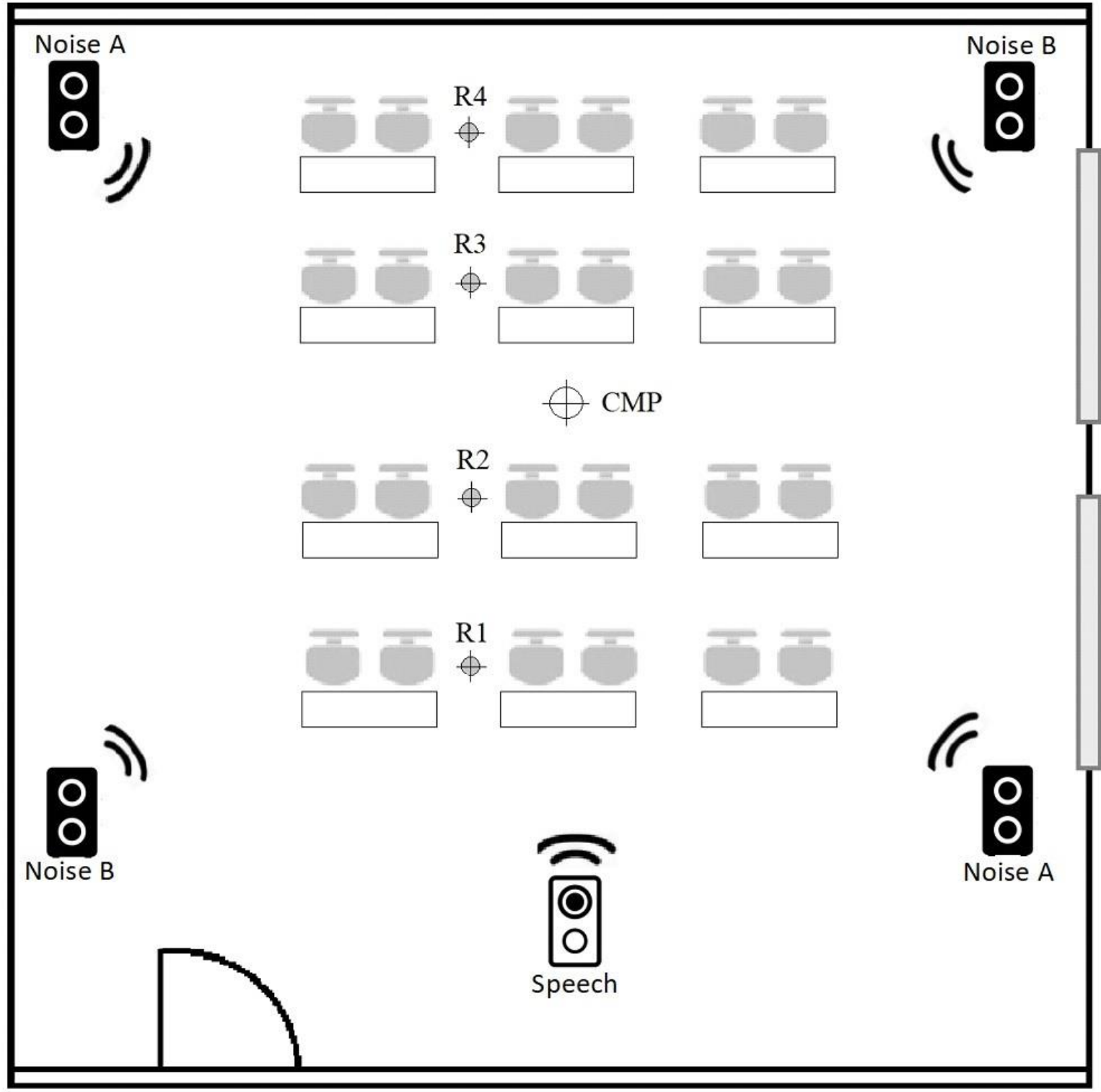

716

717 Note. Noise A and Noise B refer to the same chain of classroom noise, which was time-shifted

718 (i.e., different starting points). $\mathrm{R}=$ measurement points in each seat row ( $\mathrm{R} 1$ to $\mathrm{R} 4$ ); $\mathrm{CMP}=$

719 central measurement position. 
Figure 3

721 Mean task performance as a function of voice quality in the speech perception task (left) and the

722 listening comprehension task (right). Error bars represent SE.

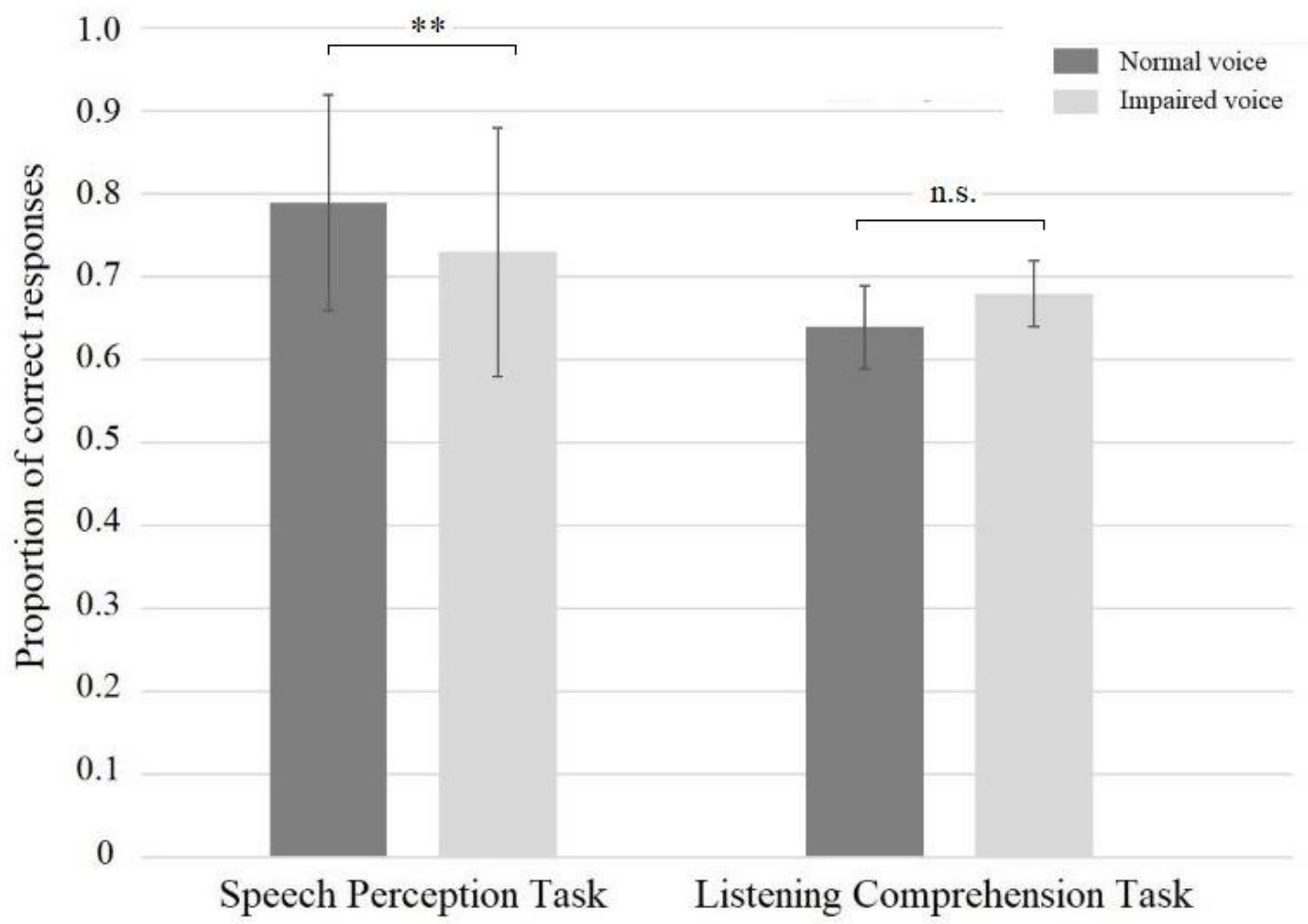




\section{$724 \quad$ Figure 4}

725 Mean task performance as a function of voice quality and task demands in the listening

726 comprehension task. Error bars represent SE.

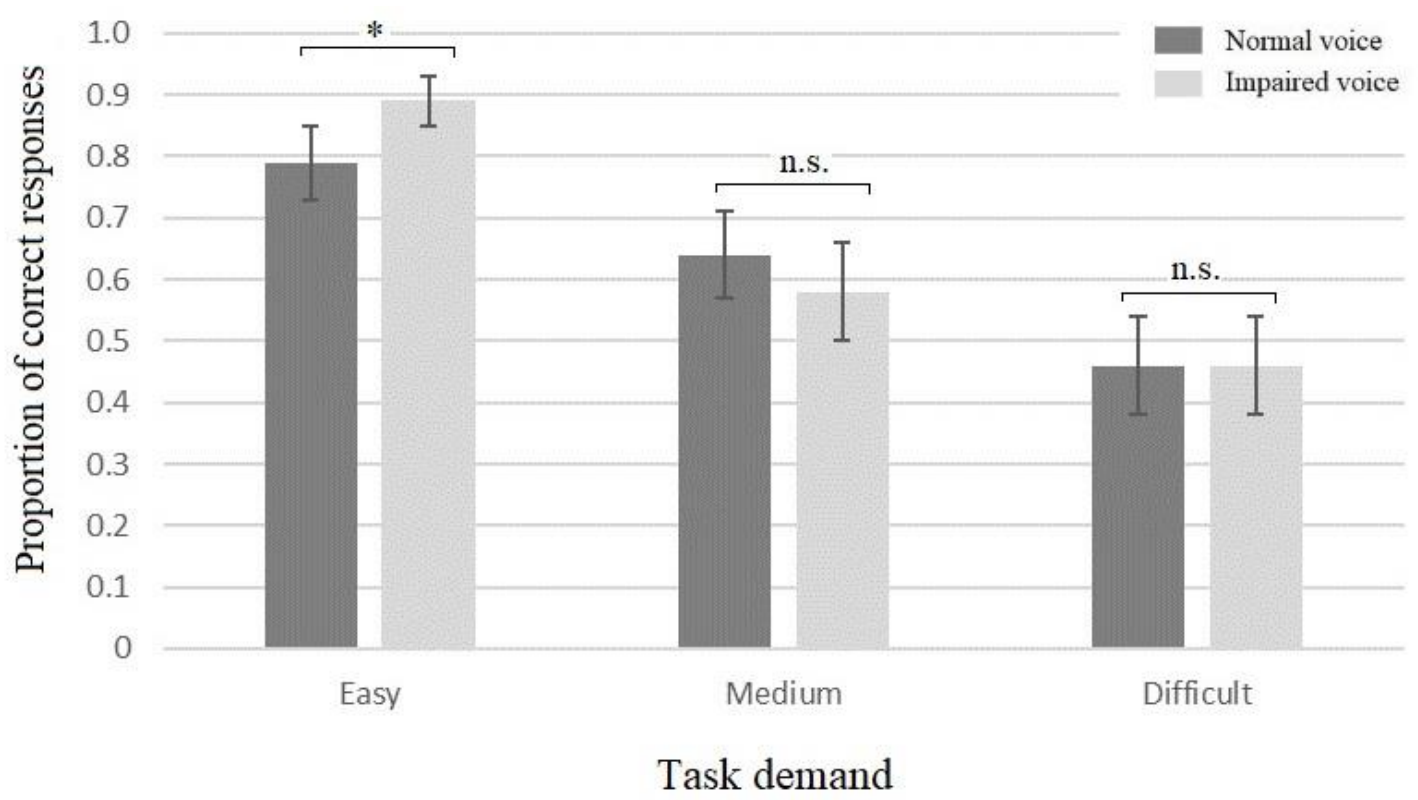

728 


\section{Figure 5}

730 Mean task performance as a function of estimated SNR unit in the speech perception task (left)

731 and the listening comprehension task (right). Error bars represent SE.
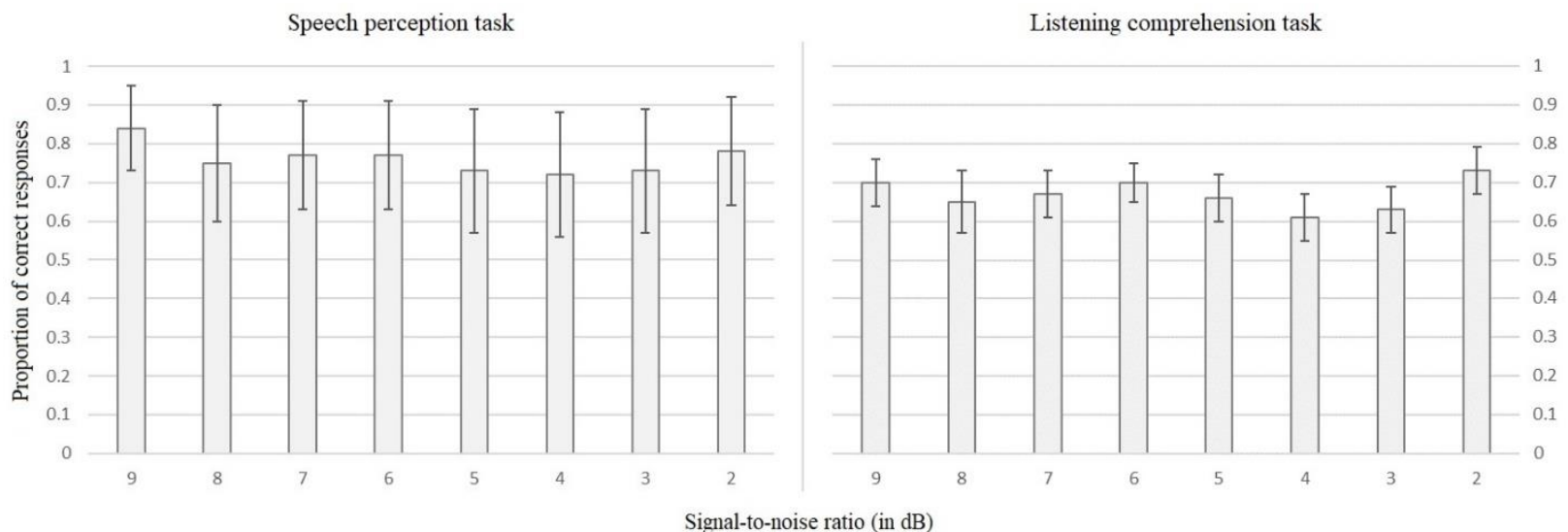

Signal-to-noise ratio (in $\mathrm{dB}$ ) 


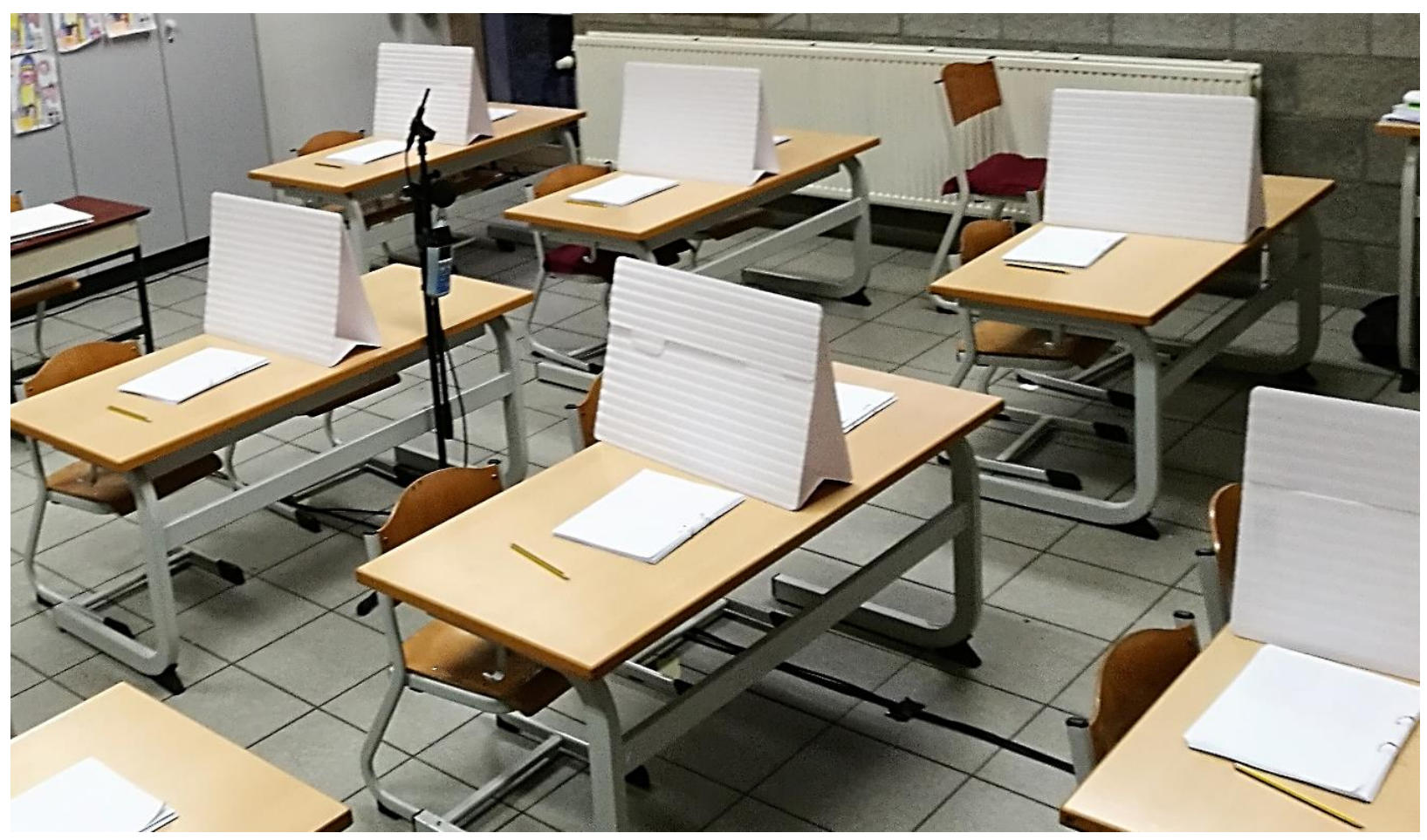

736 Note. The purpose of the screens was to prevent children from copying their neighbors' answers.

737 Each child received an answer booklet and a pen. 